\title{
Resistance Coefficients
}

and Velocity Distribution Smooth Rectangular Channel

GEOLOGICAL SURVEY WATER-SUPPLY PAPER 1592-A

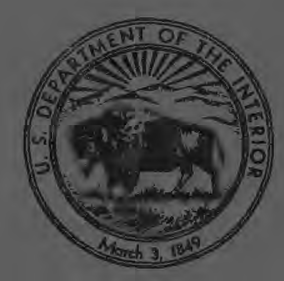

Property of

U.S. GEGLOGICAL SUINEY WATER RESOURCES DIVISION GROUND WATER BRANCH 


\section{Resistance Coefficients}

\section{and Velocity Distribution}

Smooth Rectangular

\section{Channel}

By H. J. TRACY and C. M. LESTER

LABORATORY STUDIES OF OPEN-CHANNEL FLOW

GEOLOGICAL SURVEY WATER-SUPPLY PAPER 1592-A

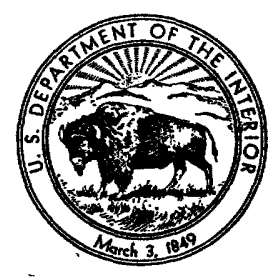




\section{UNITED STATES DEPARTMENT OF THE INTERIOR}

STEWART L. UDALL, Secretary

\section{GEOLOGICAL SURVEY}

Thomas B. Nolan, Director 


\section{CONTENTS}

Symbols

Abstract.....

Introduction .............. 1

Theoretical considerations _........ 2

Apparatus and procedure..... 5

Results.................... 8

Variation of the friction factor in subcritical flow . . . .

Variation of the friction factor in supercritical flow . .

Velocity distribution.

References cited... 18

\section{ILLUSTRATIONS}

Fraure 1. Average configuration of bottom and sides of flume $\ldots . . . \quad$ Page

2. Flume deflection under load................. 7

3. Typical surface profiles_._.

4. Variation of the friction factor in subcritical flow

5. Variation of the friction factor in supercritical flow ........ 12

6. Surface-wave amplitude relative to flow depth............. 13

7. Typical vertical-velocity distribution in the central region of flow

8. Width-depth ratio of wall region as function of channel aspect ratio . . . . .

9. Point velocity in central region related to local wall shear.....-

10. Point velocity in central region related to average wall shear.-

11. Dimensionless velocity distribution......

\section{TABLES}

TABLE 1. Data summary, subcritical flow

2. Data summary, supercritical flow 


\section{SYMBOLS}

$A$-Area of channel cross-section

$b$-Width of rectangular flume

$C$-A constant

$e$-A constant; natural logarithm base

$f$-Friction factor, $8 \mathrm{RS}_{0} q / \mathrm{U}^{2}$

$\boldsymbol{F}$-Froude number, $U / \sqrt{g y}$

$g$-Acceleration caused by gravity

$k$-Universal constant

$l$-Mixing length

ln-Logarithm to the base $e$

log-Logarithm to the base 10

$P$-Wetted perimeter

$R$-Hydraulic radius, $A / P$

$\boldsymbol{R}$-Reynolds number, $4 R U / \nu$

$r_{o}$-Pipe radius

$S_{o}$-Hydraulic gradient

$u, v, w$-Time-averaged velocity components in the $\mathrm{x}, \mathrm{y}, \mathrm{z}$ directions, respectively

$u^{\prime}, v^{\prime}, w^{\prime}$-Fluctuating components of velocity in the $\mathrm{x}, \mathrm{y}, \mathrm{z}$ directions, respectively

$U$-Average velocity in flume cross-section

$U_{c}$-Average velocity in central region of flow

$\bar{u}_{*}$-Average "shear" velocity, $\sqrt{R S_{0} g}=\sqrt{\bar{\tau}_{0} / \rho}$

$u_{*}$ - "Local" shear velocity, $\sqrt{y_{0} S_{0} g}$

$V$-Resultant point velocity

$x, y, z$-Cartesian coordinates. Distances in the $\mathrm{x}$-direction are measured along the longitudinal axis of the flume, the $y$-direction is normal to the flume floor, the z-direction is normal to the flume sidewalls.

$y_{m}$-Distance from wall at which $u=0$

$y_{0}$-Uniform depth of flow

$Z$-Width of wall region

$\rho$-Mass density

$\nu$-Kinematic viscosity

$\mu$-Dynamic viscosity

$\eta$-Eddy viscosity

$\tau$-Shearing stress 


\title{
LABORATORY STUDIES OF OPEN-CHANNEL FLOW
}

\section{RESISTANGE COEFFIGIENTS AND VELOGITY DISTRIBU- TION, SMOOTH REGTANGULAR GHANNEL}

\author{
By H. J. Tracy and C. M. Lester
}

\begin{abstract}
Measurements were made in a smooth rectangular channel to establish the effect of the side walls of the channel on velocity distribution and resistance to flow. The velocity distribution in the central region of a section normal to the channel followed the logarithmetic law. In the vicinity of each wall, at a point in the vertical which varied with distance from the wall, the slope of the vertical velocity curve reversed. The velocity distribution over the entire section has been defined in dimensionless terms. As well, the width-depth ratio for the wall region is expressed as a function of a similar ratio for the channel.

The variation of a resistance coefficient computed from the measurements is shown to be a function of the flow Reynolds number. The resistance coefficient, for the same Reynolds number, is slightly greater than for smooth pipe or a smooth channel of infinite width.
\end{abstract}

\section{INTRODUCTION}

Except for the effects of the free surface, the laws which govern the motion of fluids in closed conduits are equally applicable to uniform open channel flow. Rapid advances have been made in recent years on the problem of flow in circular closed conduits. A similar progress has not been made in the field of open channel flow, because of the additional complexities introduced by the presence of the free surface and by the usually asymmetrical cross section. Comparatively few systematic investigations have been made in open channels since the monumental work of Bazin over a century ago.

This is a report of the progress, to date, on a study of the uniform flow of water in rigid open channels. The project is a part of the research program of the U.S. Geological Survey. Experimental work is being conducted in the hydraulics laboratory of the Georgia Institute of Technology, under a cooperative agreement with the Georgia Tech Research Institute. C. E. Kindsvater, Regents Professor of Civil Engineering at Georgia Tech, is consultant to the research program.

The initial phases of the study have been concerned with the determination of the relationship between the uniform flow depth, dis- 
charge, and slope in a rectangular, smooth channel, and with the measurement of time-averaged point velocities in the flume cross section at various depths of flow and discharges. Both subcritical and supercritical flows have been considered.

\section{THEORETICAL CONSIDERATIONS}

The Navier-Stokes equations for turbulent flow may be derived from those for the laminar condition by the substitution for each velocity and pressure term a mean value and the instantaneous deviation therefrom. The time average of the resulting expressions differ from the original equations only by the addition of terms involving the time-averaged velocity fluctuations. The terms thus added are commonly referred to as "apparent" or Reynolds stresses.

The modified Navier-Stokes equations, together with the differential equation of continuity, are a starting point for the calculation of turbulent flows. There are many more unknowns than equations, however. The direct measurement or prediction of the quantities which involve the turbulent fluctuations has proven to be an almost insurmountable obstacle because of the random and extremely complicated nature of the turbulence. During the last decade, the development of the hot-wire anemometer has permitted the measurement of a number of the statistical properties of fluid turbulence to be made in air flow. A comparable instrument has not yet been developed for use in water.

The determination of the mean flow properties of the fluid are usually the eventual objective of the worker concerned with turbulent flow. Because of this, and because of the difficulties encountered in the direct solution of the Navier-Stokes equations, attempts have been made in the past to simplify the equations by the development of empirical relationships between the Reynolds stresses and the mean values of the velocity components. Some success in this direction has been attained.

Boussinesq (1897) apparently was among the first to use this approach. Except that in the one case, mixing takes place on a molecular scale, while in the other, masses of fluid are interchanged between neighboring flow regions, the shear processes in laminar and turbulent flow are approximately similar.'Boussinesq suggested that the shear stress in turbulent flow could be represented as the sum of a stress due to purely molecular viscosity and a stress due to the turbulent transfer of momentum, thus:

$$
\tau=(\mu+\eta) \frac{d u}{d y}=\mu \frac{d u}{d y}-\rho \overline{u^{\prime} v^{\prime}}
$$


In this equation, the factor $\eta$, by analogy with the molecular viscosity $\mu$, has the significance of a viscosity coefficient; and has been called the "virtual" or "apparent" viscosity. It is not, unfortunately, like $\mu$, a property of the fluid itself, but instead varies with the magnitude of the turbulence fluctuations.

Prandtl (1925) carried this approach a step further. By assuming that the momentum of each fluid particle remains unchanged during movement from one region to another, he postulated, for a twodimensional flow:

$$
\tau=\rho l^{2}\left(\frac{d u}{d y}\right)^{2}
$$

in which $l$ is the mixing length; the average migration distance of particles of fluid starting from a given point. This statement is equivalent to an assumption regarding the value of the apparent viscosity, thus:

$$
\eta=\rho l^{2}\left(\frac{d u}{d y}\right)
$$

By assuming that the mixing length is proportional to the distance from the wall, $y$, and that, near the wall, $\tau$ is equal to $\tau_{0}$, the mixing length hypothesis becomes:

$$
\tau_{0}=\rho k^{2} y_{0}^{2}\left(\frac{d u}{d y}\right)^{2}
$$

which may be integrated to give the logarithmic vertical-velocity distribution,

$$
\frac{u}{\sqrt{\tau_{0} / \rho}}=\frac{1}{k} \ln y+C_{1}
$$

in which $k$ is a constant. Because of the assumption regarding $\tau_{0}$, the integrated expression is applicable only to the wall region. Experimental data, however, confirm the fact that it is a better description of the distribution of velocity away from the wall region than it is near the wall. Rouse (1959) suggests that it is just as reasonable to assume that,

$$
l=k y \sqrt{1-\frac{y}{y_{0}}}
$$

wnich eliminates the inconsistency, since $\tau=\tau_{0}\left(1-\frac{y}{y_{0}}\right)$. 
Taylor (1935), using a vorticity-transport concept, derived an expression applicable to free-turbulence flow almost identical to that given by Prandtl for turbulent flow near a fixed boundary. Von Karman (1931) basing his deductions upon the experimentally confirmed assumption that the correlation between the fluctuating components of flow in pipes remains constant almost from the center of the pipe to the region of the wall, concluded that the turbulent mechanism over this region is similar, and further, that it differs only in the time and length scales from the turbulence in any other pipe, regardless of size and boundary roughness. From this, he developed a relationship between the mixing length and certain characteristics of the mean flow. His expression is more complicated than that of Prandtl; when integrated, however, it leads to the logarithmic distribution under the assumption that $\tau$ is constant and equal to $\tau_{0}$.

The mixing-length theories have lately fallen into disrepute. They contain the implicit assumption that what is locally produced is locally dissipated, whereas in actuality the production of turbulent energy and its ultimate conversion into molecular heat are the initial and the final phase of a complex process, and do not coincide spatially. The mixing-length concept has lost much of its importance because the mean-velocity distribution may also be obtained from simple dimensional considerations. Probably no completely adequate theory will be forthcoming until more is known about the origin and structure of turbulence. Until such time, however, these concepts will continue to be useful and convenient tools.

The constant of integration of equation (1) may be obtained from the condition that $u=0$ at a certain distance from the wall, say at $y=y_{m}$. Then

$$
u=\frac{u_{*}}{k}\left(\ln y-\ln y_{m}\right)
$$

For flow near smooth walls, the motion pattern is determined by $\nu$ and $u_{*}$. It may be concluded, therefore, that $y_{m}$ is proportional to the ratio of $u_{*}$ and $\nu$, which has the dimension of a length. Then

$$
y_{m} \alpha \frac{\nu}{u_{*}}
$$

or

$$
\frac{u}{u_{*}}=\frac{1}{k} \ln \frac{y u_{*}}{\nu}+C_{2}
$$

the constants $k$ and $C_{2}$ have been determined by Nikuradse (1932) from experiments on smooth pipes. Substituting the experimentally 
determined values into the equation, and converting to common logarithms, the expression becomes

$$
\frac{u}{u_{*}}=5.75 \log \frac{y u_{*}}{\nu}+5.5
$$

Equation (2) may be integrated across a normal pipe section to determine the rate of flow. The mean velocity, $U=Q / A$, is

$$
U=u_{*}\left(5.75 \log \frac{u_{*} r_{0}}{\nu}+1.75\right)
$$

or, in terms of the hydraulic radius, $R=A / P=r o / 2$

$$
\frac{U}{u_{*}}=5.75 \log \frac{R u_{*}}{\nu}+3.50
$$

or

$$
\frac{1}{\sqrt{f}}=2.03 \log R \sqrt{f}-0.91
$$

where $\boldsymbol{R}=2 U r_{\mathrm{o}} / \nu=4 R U / \nu$.

A similar integration over the half-section of an infinitely wide conduit having parallel, smooth walls leads to the relationship:

$$
\frac{1}{\sqrt{f}}=2.03 \log R \sqrt{f}-1.08
$$

In equation (5), the Reynolds number, to be consistent with that for flow in pipes, is equal to $4 R U / \nu=4 y_{0} U / \nu$, where $y_{0}$ is the half-width of the section.

In following sections of this report, the equations developed from the integration of the Prandtl mixing length hypothesis will be compared with the results obtained in the smooth, rectangular open test channel, in order to ascertain the combined effects of the free surface and the secondary motions which exist in the open channel.

\section{APPARATUS AND PROCEDURE}

The laboratory tests were made in a steel flume $3 \frac{1}{2}$ feet wide, 18 inches deep, and 80 feet long. The flume is supported at its midpoint on a fixed pivot and at the two ends by pairs of screw jacks. An electric motor at the pivot drives the two pairs of jacks simultaneously through torque tubes of equal length. The drive mechanism also furnishes a method for the determination of the flume slope. 
The number of turns made by the torque tubes from the level flume position is indicated by a mechanical counting device. The vertical displacement of the two ends of the flume for various counter readings has been measured by precise levels. A calibration of counter reading against flume slope has been prepared from this data and the measurement of the distance between the two end points.

Two longitudinal, variable-depth, built-up steel beams furnish the principal support for the flume box. Two 4-inch channels placed back-to-back are welded in place on top and across the beams at 3 -foot intervals. Five lengths of threaded $3 / 4$-inch rod, inserted vertically between each channel pair and spaced at equal intervals, are held in place by nuts bearing on the top and bottom of the channels. The rods project to a height of about 3 inches above the top of the channels, and form bearing supports for five small car channels which extend the length of the flume. The flume floor is bolted directly to the car channels. Small irregularities in the flume floor as well as the curvature due to the dead weight deflection of the supporting beams may be removed by adjustments in the height of the tops of the threaded rods. The side walls are supported by channel lengths welded to the angles that form the bottom support for the side plates. The channel lengths are vertical, and on 3 foot centers. Bolts tapped through the channels permit slight adjustments to be made in the position of the side walls. The inner flume surfaces are covered by one seal coat and two coats of synthetic enamel, applied by brush.

Before tests were made in the flume, the bottom and sides of the flume were adjusted to make them as plane as possible. Precise levels were run to determine the variation of the bottom and where necessary, the bottom elevation adjusted by means of the supporting rods under the flume floor. Figure 1 shows the average configuration of the bottom and sides of the flume after the adjustments were made.

The deflection characteristics of the flume under various depths of flow are shown in figure 2. The deflection is inconsiderable except at the extreme downstream end of the flume at depths greater than one-half foot of water. Tests thus far in the flume have been limited to depths equal to or less than one-half foot.

Water surface levels are read by point gages from a carriage which moves on rails mounted on the top of the sidewalls of the flume. Piezometer openings have also been installed in the flume floor.

Water is supplied to the flume by the laboratory recirculating system through either a 12-inch or a 6-inch line. Discharges are measured by a venturi meter located in the 12 -inch line, or by an orifice meter located in the 6-inch line. Both meters were calibrated gravimetrically. 


\subsection{0}

3.485

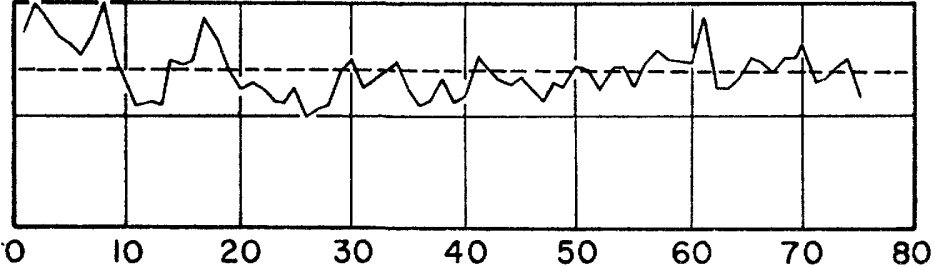

Distance along flume, feet

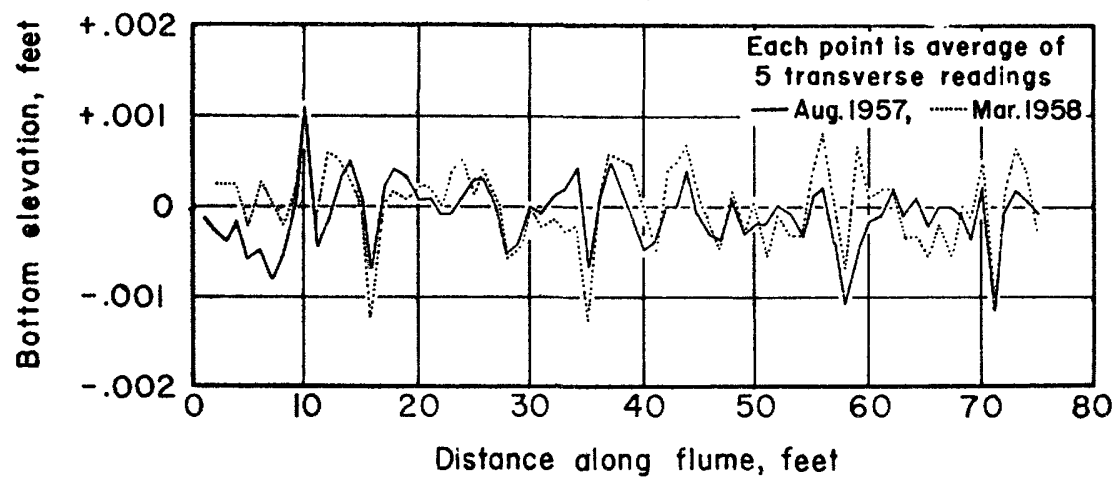

Fraure 1.-Average configuration of bottom and sides of flume.

The depth of flow in the flume is regulated by an adjustable tailgate, or by a sluice gate at the entrance to the flume. Point velocities have been measured with small pitot tubes, or by stagnation tubes used in conjunction with floor piezometers.

Near the normal depth, steady flow in uniform channels varies gradually from section to section. The change may be almost imperceptible over short distances as, for example, the 80 feet of length of the experimental flume. For mild channel slopes, the normal surface-

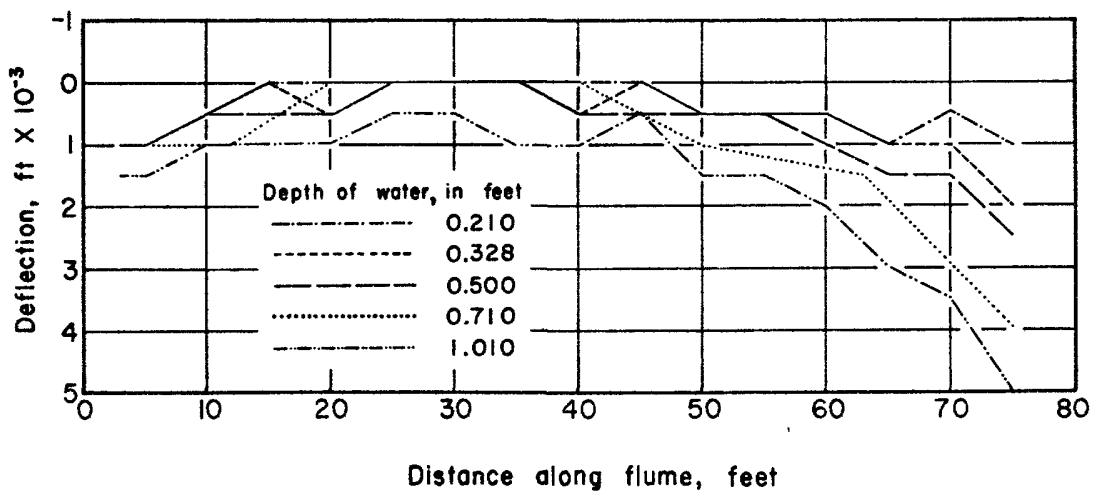

Figure 2,-Flume deflection under load. 
profile is the upstream asymptote to the $M 1$ and the $M 2$ backwater curves. For steep slopes, the normal profile is the downstream asymptote to the $S 2$ and the $S 3$ curves. In each case, the normal line lies between the two curves. The method used to determine the normal flow depth consisted of the measurement of the surface profile at depths just greater than the normal, and at depths just smaller than the normal. The normal depth was then interpolated between the two curves. Point gage readings to the nearest 1-1000th of a foot were made at five points in cross sections at one-foot intervals for the length of the flume. The point-gage readings were compared with the piezometric level at selected points in the flume. The normal flow depth has been referenced to the piezometric level for tests in which the flow was subcritical. For the supercritical flow tests, in which the velocities were generally considerably greater than those in the subcritical range, the piezometric height is more difficult to measure accurately. For these runs, a mean depth based upon pointgage readings was computed. This will be discussed in a later section.

The normal depth of flow for a zero slope is infinite. Small slope changes at slopes close to the horizontal correspond to large changes in normal depth. Because of this, an apparently normal flow profile may be obtained over a comparatively large change in depth at the smaller slopes (see figure 3a). At these slopes, therefore, the interpolated value of the normal depth is somewhat less reliable than at greater slopes.

On the other hand, at very steep slopes and at small depths, very large changes in slope are required to cause perceptible changes in depth. Errors in the measurement of depth assume a relatively greater importance at steep slopes. At these depths and slopes, therefore, it becomes important to observe $S 2$ and $S 3$ curves as close as possible to the normal profile in order that the error in estimating the normal depth be minimized. A typical set of measurements of flow on a steep slope is illustrated in figure $3 B$.

\section{RESULTS}

In all, 49 uniform flow tests have been made in the rectangular smooth flume. Twenty-four of the tests were in the subcritical flow range, and 25 in the supercritical flow range. The depth of flow was varied from 0.1 to 0.5 feet, the discharge from $0.3 \mathrm{cfs}$ to $7.3 \mathrm{cfs}$. The principal results from the tests are shown in tables 1 and 2.

The flow Reynolds number, $4 R U / \nu$, is approximately proportional to the discharge per foot of width of the flume. The Reynolds number, for the discharge range tested, varied from about 35,000 to about 700,000 . 


\section{VARIATION OF THE FRICTION FACTOR IN SUBCRITICAL FLOW}

The results of the twenty-four tests made in the subcritical flow range are shown on figure 4. For comparative purposes, equation (4), for turbulent flow in smooth pipes; and equation (5), for flow near smooth, parallel walls are also shown. The line drawn through the open-channel flow-data is described by the equation

$$
\frac{1}{\sqrt{\mathfrak{f}}}=2.03 \log \boldsymbol{R} \sqrt{\mathfrak{f}}-1.30
$$

which differs from the closed-conduit relationship only in the magnitude of the constant. Equation (6) may also be written:

$$
\frac{U}{\bar{u}_{*}}=2.40+5.75 \log \frac{R^{-} *}{\nu}
$$

in which $\bar{u}_{*}$ is the average "shear" velocity, $\sqrt{\overline{\tau_{0} / \rho}}=\sqrt{R S_{0}} g ; \mathrm{R}$ is the hydraulic radius, $A / P$; and $U$ is the average velocity in the flume cross-section. The average deviation, in terms of $f$, of the plotted points from the line defined by equation (6) is less than one percent.

\section{VARIATION OF THE FRICTION FACTOR IN SUPERCRITICAL FLOW}

The typical free surface in supercritical flow is characterized by highly agitated transverse waves of short length. The amplitude
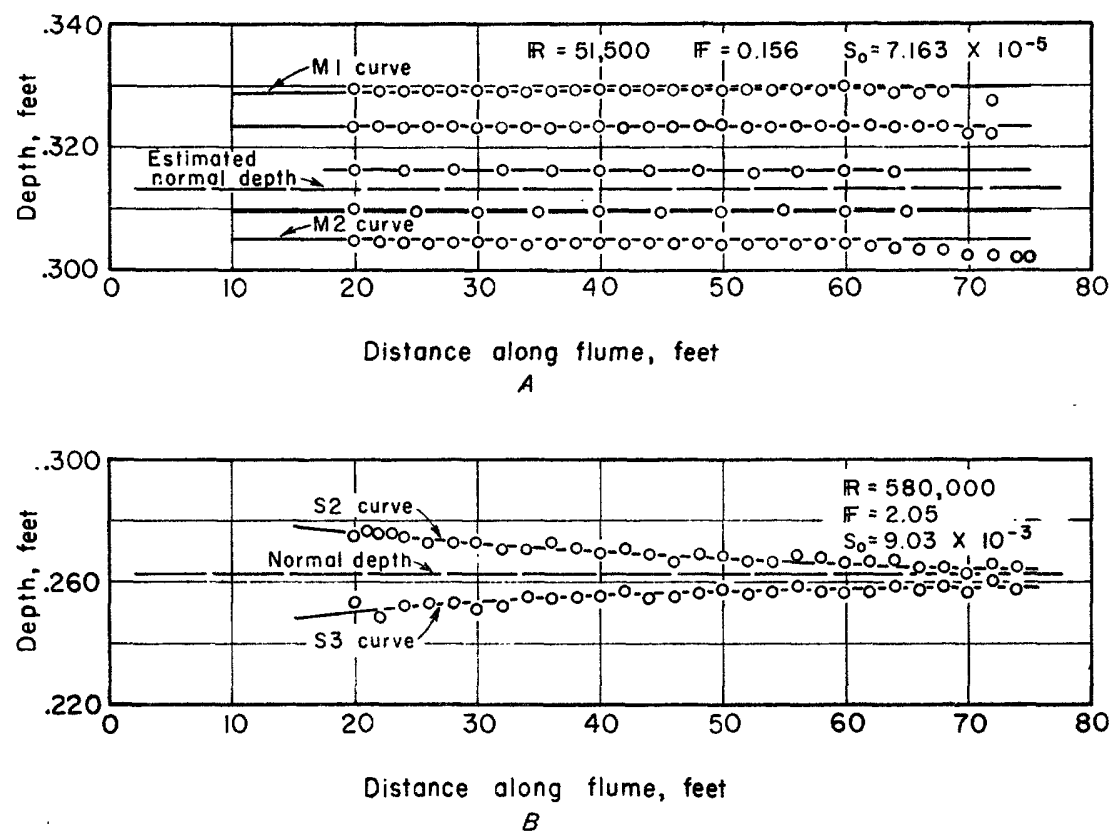

Fraure 3.-Typical surface profiles. 
TABLE 1.-Summary of data, subcritical flow

\begin{tabular}{|c|c|c|c|c|c|c|c|c|}
\hline Run & $\begin{array}{c}Q \\
\text { (cfs) }\end{array}$ & $\stackrel{y_{0}}{y_{0}}$ & $S_{0} \times 10^{+4}$ & $\begin{array}{c}T \\
\text { (degrees } \\
\mathbf{F} \text { ) }\end{array}$ & $\left(\begin{array}{c}2 \times 10^{+6} \\
\left(\mathrm{ft}^{2} \text { per sec. }\right)\end{array}\right.$ & $f$ & $\boldsymbol{R}$ & $F$ \\
\hline $1 \ldots$ & 1. 21 & 0.300 & 3. 799 & 74 & 1.005 & 0.0188 & 117,800 & 0.372 \\
\hline $2 \ldots$ & 2. 98 & .503 & 4.680 & 73 & 1.018 & .0163 & 260,700 & .423 \\
\hline 3... & 1.99 & $.26 \%$ & 13.21 & 67 & 1.104 & .0172 & 179,300 & .730 \\
\hline $4 \ldots . .$. & 2.01 & .303 & 9.195 & 67 & 1. 104 & .0169 & 177,900 & .610 \\
\hline $5 \ldots \ldots$ & 2.00 & .353 & 6.057 & 65 & 1. 134 & .0172 & 172,400 & .483 \\
\hline $6 \ldots$ & 1.99 & .399 & 4. 295 & 65 & 1. 134 & .0176 & 163,800 & .390 \\
\hline $7 \ldots \ldots$ & .498 & .313 & .7158 & 77 & .967 & .0235 & 51,510 & .144 \\
\hline $8 \ldots \ldots+\ldots$ & 1.50 & .407 & 2.423 & 72 & 1.032 & .0184 & 134,700 & .292 \\
\hline $9 \ldots$ & 2.00 & .401 & 4. 188 & 69 & 1.074 & .0172 & 173,700 & .398 \\
\hline $10 \ldots$ & 2. 50 & .402 & 6. 277 & 69 & 1.074 & .0166 & 217,000 & .497 \\
\hline $11 \ldots$ & 3. 54 & .413 & 11.07 & 70 & 1.059 & .0157 & 310,100 & .677 \\
\hline $12 \ldots \ldots$ & 4.01 & .418 & 13. 16 & 70 & 1.059 & .0151 & 350,400 & $.7 B 0$ \\
\hline $24 \ldots$ & 1.03 & .429 & 1.101 & 70 & 1.059 & .0206 & 89,520 & .186 \\
\hline $30 \ldots$ & 5. 59 & .454 & 19.22 & 78 & .954 & .0142 & 533,400 & .922 \\
\hline $34 \ldots$ & 3. 80 & .496 & 6.497 & 78 & .954 & .0158 & 327,600 & .507 \\
\hline $40 \ldots \ldots$ & 1.98 & .503 & 2. 147 & 79 & .942 & .0170 & 187,100 & .281 \\
\hline $41 . \ldots$. & 1. 46 & .206 & 15.64 & 79 & .042 & .0180 & 158,900 & .787 \\
\hline 42 & 1.00 & .146 & 21. 14 & 79 & .942 & .0191 & 112,300 & .903 \\
\hline $43 \ldots$ & 1.00 & .215 & 6.938 & 79 & .942 & .0192 & 108,100 & .507 \\
\hline $45 \ldots$ & .370 & .107 & 9.532 & 72 & 1.032 & .0251 & 38,730 & .535 \\
\hline $46 \ldots$ & .372 & .223 & 1.157 & 70 & 1.059 & .0257 & 35,720 & .179 \\
\hline $47 \ldots$ & .400 & .100 & 12.95 & 75 & .991 & .0242 & 43,770 & .636 \\
\hline $48 \ldots$ & .700 & .148 & 11.02 & 77 & .967 & .0208 & 76,540 & .625 \\
\hline $50 \ldots$ & .398 & .148 & 4. 132 & 77 & .967 & .0242 & 43,510 & .355 \\
\hline
\end{tabular}

TABLE 2.-Summary of data, supercritical flow

\begin{tabular}{|c|c|c|c|c|c|c|c|c|}
\hline Run & $\begin{array}{c}Q \\
\text { (cfs) }\end{array}$ & $\begin{array}{c}y_{0} \\
(f e e t)\end{array}$ & $S_{0} \times 10^{+4}$ & $\underset{\text { (degrees }}{T}$ & $\left(\begin{array}{c}2 \times \times 10^{+8} \\
\left(\mathrm{ft}^{2} \text { per sec. }\right)\end{array}\right.$ & $f$ & $R$ & $F$ \\
\hline 13. & 7.33 & 0.341 & 66.12 & 77 & 0.967 & 0.0128 & 726,900 & 1.86 \\
\hline $14 \ldots$ & 2.30 & .0952 & 330.5 & 77 & .967 & .0160 & 258,800 & 3. 96 \\
\hline $15 \ldots$ & 1.78 & .0867 & 276.5 & 77 & .967 & .0169 & 201,300 & 3. 56 \\
\hline 19. & 0.796 & .0993 & 46.80 & 74 & 1.005 & .0214 & 85,970 & 1. 29 \\
\hline $20 \ldots$ & 0.597 & .0935 & 33.04 & 74 & 1.005 & .0223 & 64,880 & 1.06 \\
\hline $21 .$. & 5.00 & .186 & 195.6 & 81 & .919 & .0141 & 564,000 & 3.17 \\
\hline $22 \ldots$ & 4.50 & .192 & 148.7 & 73 & 1.018 & .0146 & 456,700 & 2. 70 \\
\hline $23 \ldots$ & 3. 98 & .195 & 115. 6 & 74 & 1.005 & .0151 & 408,600 & 2.34 \\
\hline $26 \ldots$ & 7. 18 & .456 & 29.84 & 74 & 1.005 & .0136 & 649,500 & 1.18 \\
\hline $27 \ldots \ldots$ & 7.18 & .354 & 59.46 & 74 & 1.005 & .0133 & 680,800 & 1. 72 \\
\hline $28 \ldots \ldots \ldots$ & 7.01 & .260 & 141.5 & 76 & .979 & .0137 & 714,900 & 2.68 \\
\hline 29 & 5. 69 & .359 & 38.32 & 76 & .979 & .0142 & 552,600 & 1.34 \\
\hline $31 .$. & 5.48 & .258 & 90.30 & 79 & .942 & .0141 & 581,300 & 2.20 \\
\hline $33 \ldots$ & 4. 52 & .279 & 51.04 & 80 & .930 & .0146 & 480,500 & 1.55 \\
\hline $35 \ldots$ & 3.51 & .136 & 261.1 & 78 & .954 & .0153 & 391,400 & 3. 56 \\
\hline $36 \ldots$ & 3. 01 & .172 & 95.81 & 79 & .942 & .0153 & 333,600 & 2.14 \\
\hline $37 \ldots$ & 3. 01 & .136 & 180.5 & 80 & .930 & .0154 & 344,200 & 3.03 \\
\hline $38 \ldots \ldots$ & 3.01 & .201 & 62.49 & 79 & .942 & .0157 & 328,500 & 1.69 \\
\hline $39 \ldots$ & 2.01 & .0919 & 298.0 & 79 & .942 & .0170 & 232,500 & 3.64 \\
\hline $44 \ldots$ & 1.00 & .0960 & 74.33 & 79 & .942 & .0195 & 115,400 & 1.70 \\
\hline $51 \ldots$ & .917 & .124 & 29.37 & 83 & .897 & .0197 & 109,400 & 1.06 \\
\hline $52 \ldots \ldots$ & 1. 207 & .103 & 82.65 & 81 & .919 & .0182 & 142,200 & 1.85 \\
\hline $53 \ldots$ & 1. 643 & .124 & 82.65 & 81 & .919 & .0171 & 191,500 & 1.90 \\
\hline - & .974 & .104 & 55.10 & 81 & .919 & .0191 & 114,700 & 1.48 \\
\hline $55 \ldots$ & .917 & .101 & 53.45 & 83 & .897 & .0194 & 110,800 & 1.45 \\
\hline
\end{tabular}




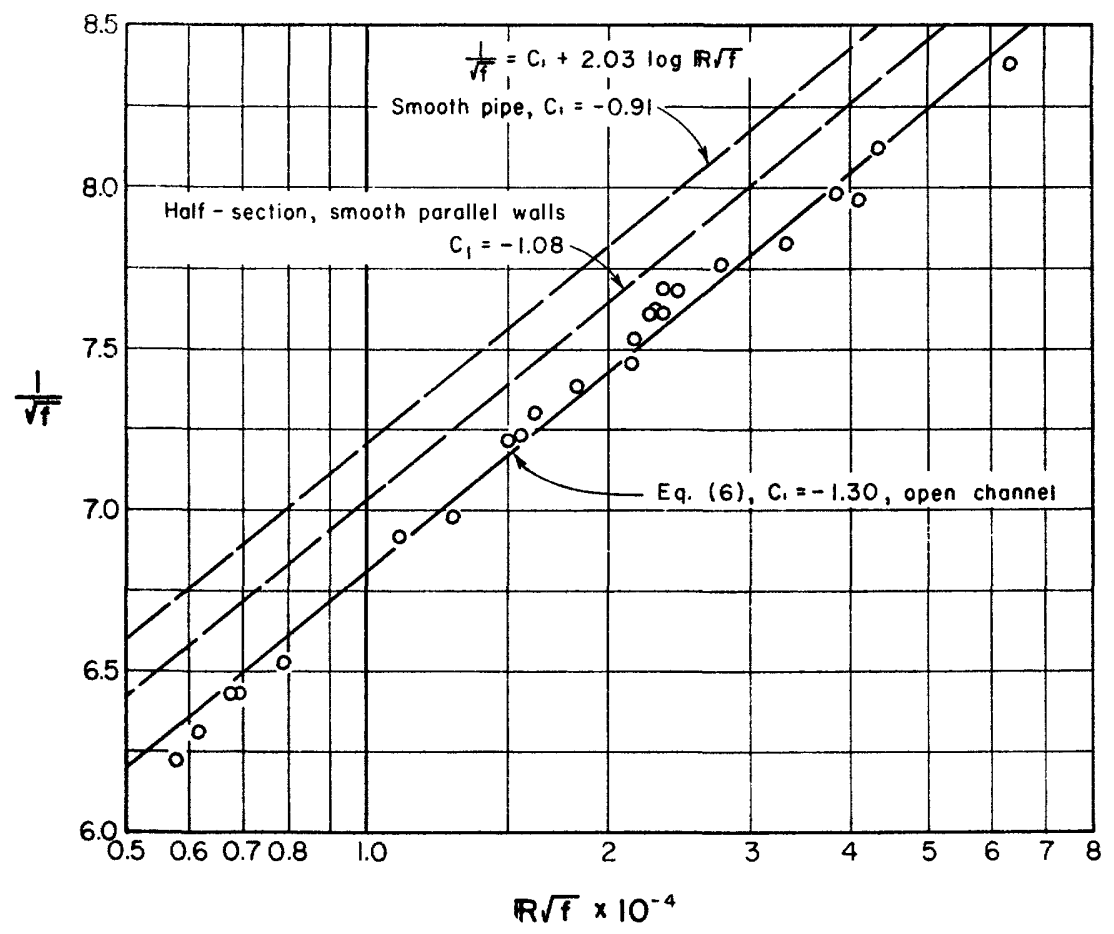

FIGURE 4.-Variation of the friction factor in subcritical flow.

and the period of the waves varies with the Froude number. The determination of the flow depth by means of point gages is influenced to some extent by the judgment of the observer. In this connection, also, the pressure indications given by floor piezometers are extremely sensitive to small imperfections in construction and alignment. Piezometric errors vary directly with the velocity head of the flow.

The mean depth for each of the test runs in supercritical flow has been experimentally established by first measuring the elevation of the crests, and next the elevation of the valleys of the wave pattern with the point gage. The mean depth has been computed as the average of the two levels thus observed. This procedure eliminates much of the judgment required in the location of the mean depth by a single reading of the point gage. It does not, however, give adequate consideration to the fact that the location of the true depth line is a function of the shape and the spacing of the waves.

The piezometric depth was measured from four floor piezometers in a section normal to the flow seventy feet from the flume entrance. Because of the high flow velocities of many of the supercritical tests, and the consequent possibility of error, the piezometric measurements were not used. It is of interest to note, however, that at all veloci- 


\section{A-12 LABORATORY STUDIES OF OPEN-CHANNEL FLOW}

ties, the depth indicated by three of the four piezometers agreed with that computed from the point-gage readings within one percent. The fourth gage read consistently low by amounts up to two percent of the point-gage depth.

The friction factors for the supercritical flow tests have been computed using the point-gage mean depth, which was determined as the mean of the elevations of the peaks and valleys of the waves. The results are shown in figure 5. The average results are described by the same function as for the subcritical tests. The mean depth is listed in table 2.

An idea of the magnitude of the wave heights for the various supercritical flow runs may be gained from figure 6 . In this figure, the mean water-surface levels computed from the point-gage readings have been subtracted from the point-gage levels for the corresponding wave peaks. The differences, or wave amplitudes, have been divided by the mean depth and the resulting ratios shown as a function of the Froude number.

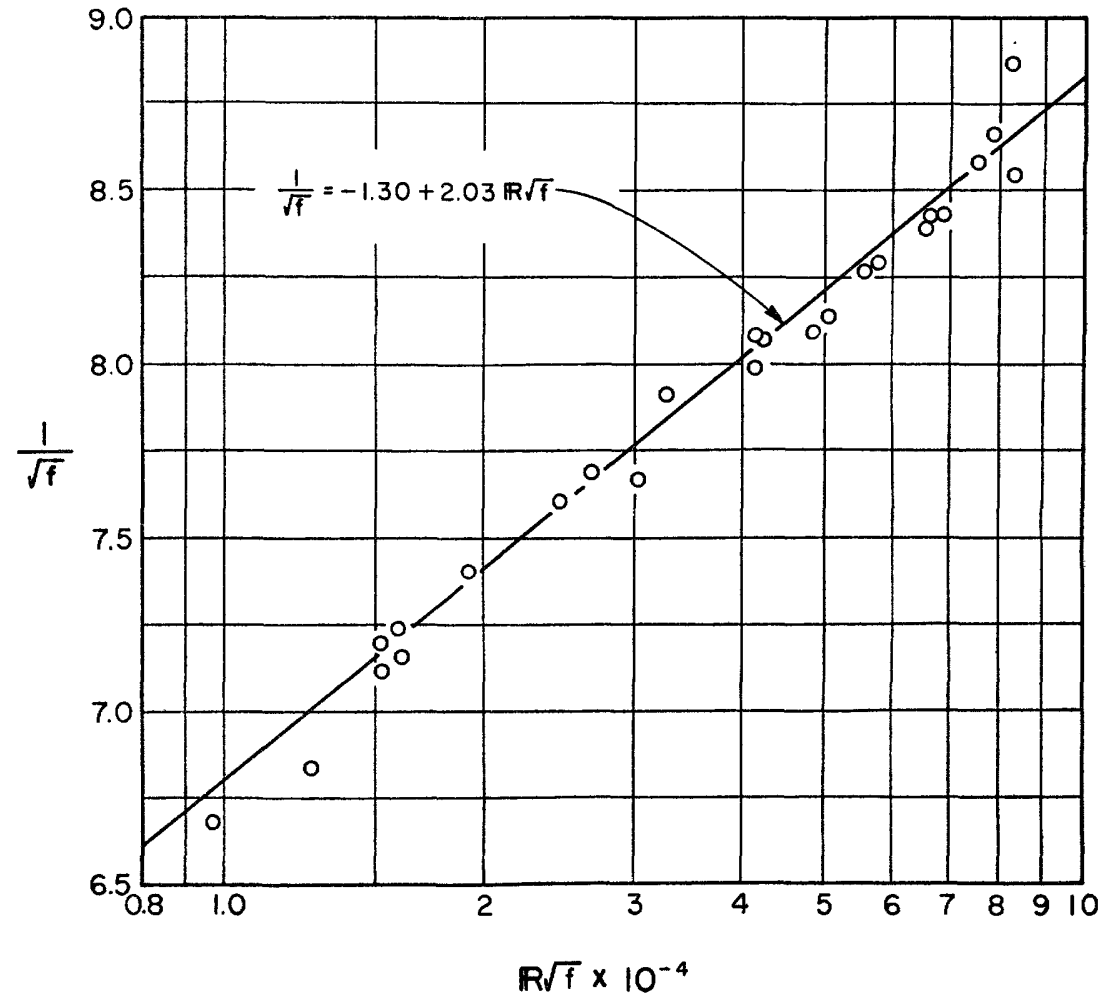

Figure 5. - Variation of the friction factor in supercritical flow. 


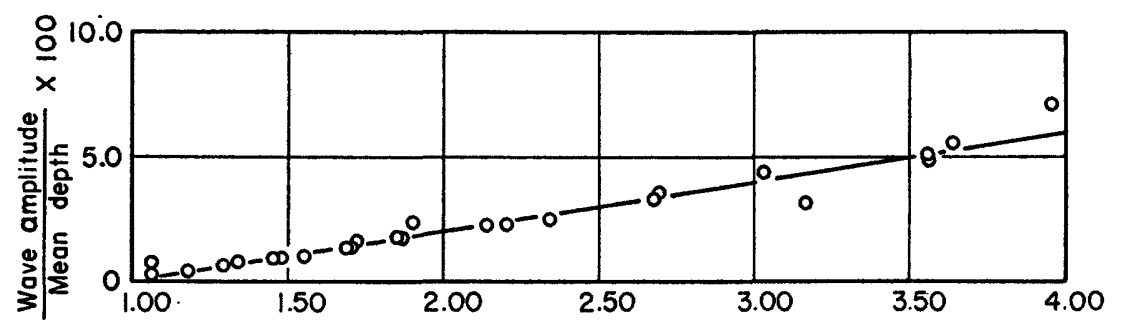

Froude number

Figure 6.--Surface-wave amplitude relative to flow depth.

\section{VELOCITY DISTRIBUTION}

Point velocity measurements were made over a section normal to the flow in the region of fully established motion at the downstream end of the flume for twenty-four of the experimental runs. The measurements were made for runs in both the supercritical and subcritical flow range, using either a small pitot-static tube $(0.0058 \mathrm{ft}$ outside diameter), or a stagnation tube $(0.0040 \mathrm{ft}$ outside diameter) in conjunction with floor piezometers. Differential pressures were measured to the nearest 0.001 inch of water. The following general conclusions have been drawn from the measurements:

1. The flow is symmetrical about the vertical plane equidistant from the two sidewalls of the flume. Each half-section may be divided into two regions; one in the central portion of the channel, and the other in the vicinity of the wall.

2. Each vertical-velocity curve in the central region of flow is logarithmic from the surface to a point very close to the floor. The velocity distribution may be expected to deviate from the logarithmic law near the laminar sublayer as purely viscous stresses become of the same order of magnitude as those due to momentum exchange. Because of the relatively large diameter of the instruments that were used, measurements in the laminar zone were not obtained. The measurements in the floor vicinity also display a greater random variation than those away from the floor, because of the relatively greater difficulties encountered in the measurement of very low velocities.

Within the limits of experimental accuracy, the vertical-velocity curves appear to be identical over the width of the central region. At a given distance from the floor, the velocity gradient $\frac{\partial u}{\partial z}$ is thus equal to or very close to zero. A typical curve for the central region is shown in figure 7 . 


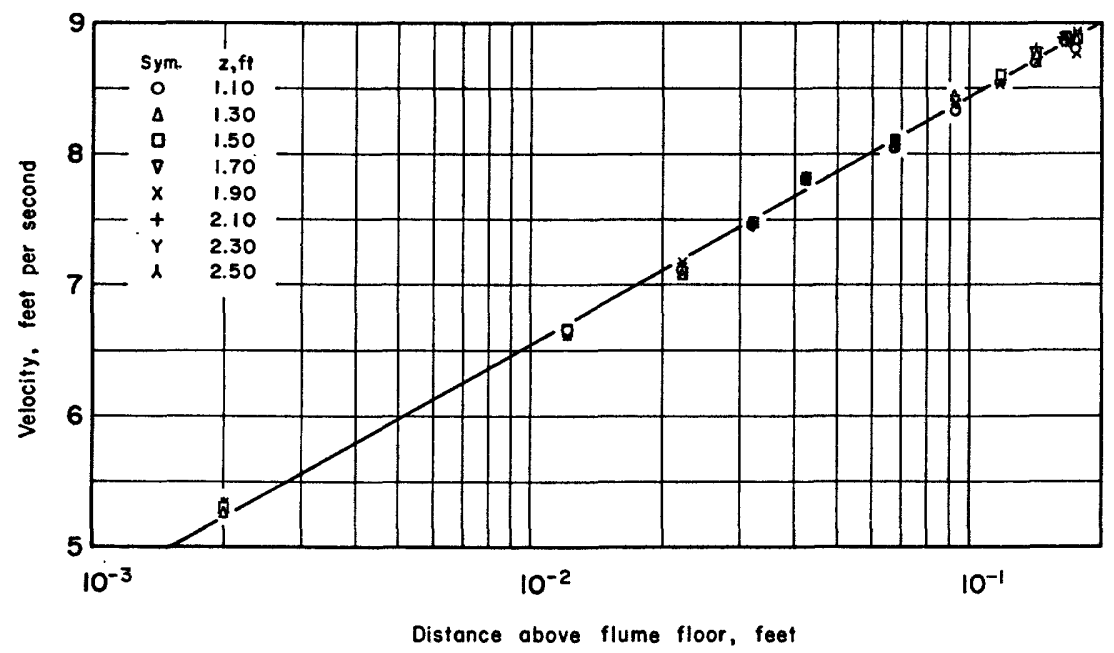

FIGURE 7.-Typical vertical-velocity distribution in the central region of flow.

3. In the vicinity of the sidewalls, the maximum velocity in each vertical is depressed below the surface.

4. In the wall region, the magnitude of the mean velocity in the vertical increases with distance from the wall.

The limits of the central region of flow have been defined as the vertical-velocity curves on either side which first deviate from the characteristic logarithmic profile. The distance from each of the boundaries to the nearest sidewall has been called $Z$. The distance $Z$ is a function of the depth-width ratio of the channel. The relationship between the channel-aspect ratio, $y_{0} / b$, and the width-depth ratio of each of the wall regions, $Z / y_{0}$, is shown in figure 8 . The precise location of the central region boundaries are difficult to ascertain experimentally, which accounts for the scatter of the points about the curve of figure 8.

The velocity distribution in the central region is shown in dimensionless form in figure 9 . The ordinate scale is the ratio of point velocity to local shear velocity, $u / u_{*}$; the abscissa scale is the dimensionless depth, $\frac{y u_{*}}{\nu}$. The test data involves both supercritical and subcritical flow. The uniform flow depth, $y_{0}$, ranges from 0.100 to $0.456 \mathrm{ft}$. The mean depth has been used in the computations for the supercritical-flow tests.

Lines have not been drawn through the points shown on figure 9. Each set of data, however, appears to define a straight line; each of which may be represented by an equation of the slope-intercept form. 
RESISTANCE COEFFICIENTS, SMOOTH RECTANGULAR CHANNEL A-15

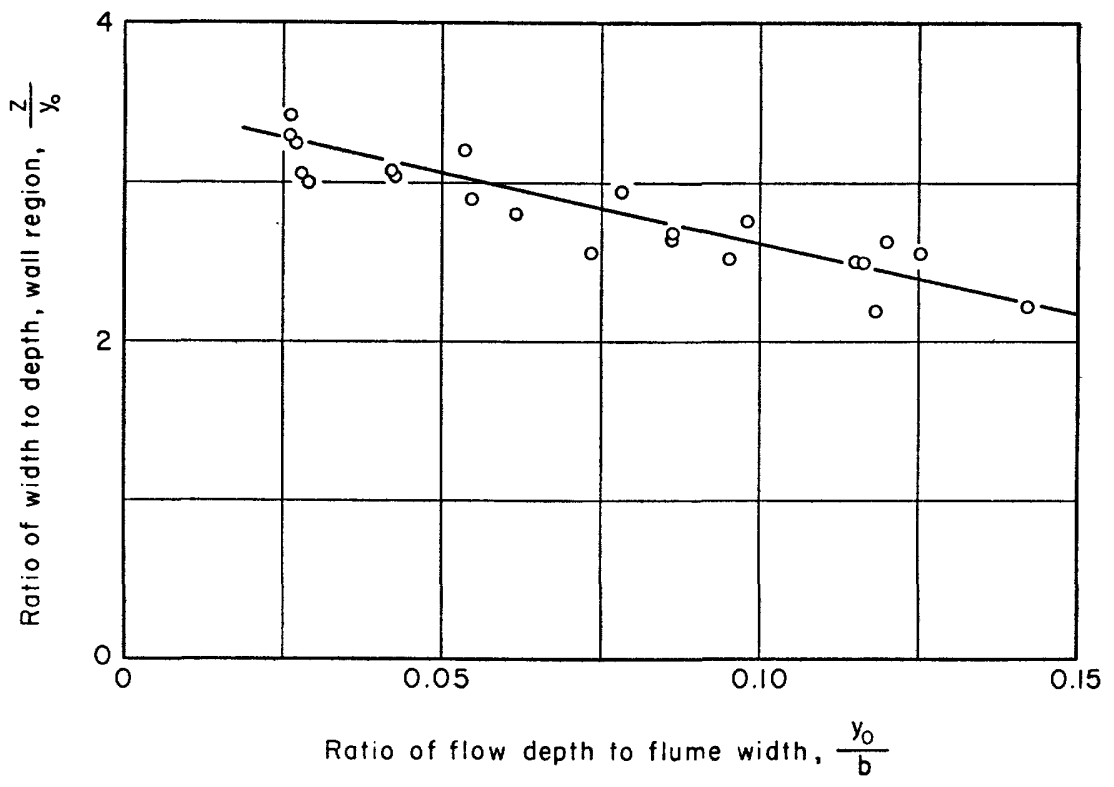

FIGURE 8.-Width-depth ratio of wall region as function of channel aspect ratio.

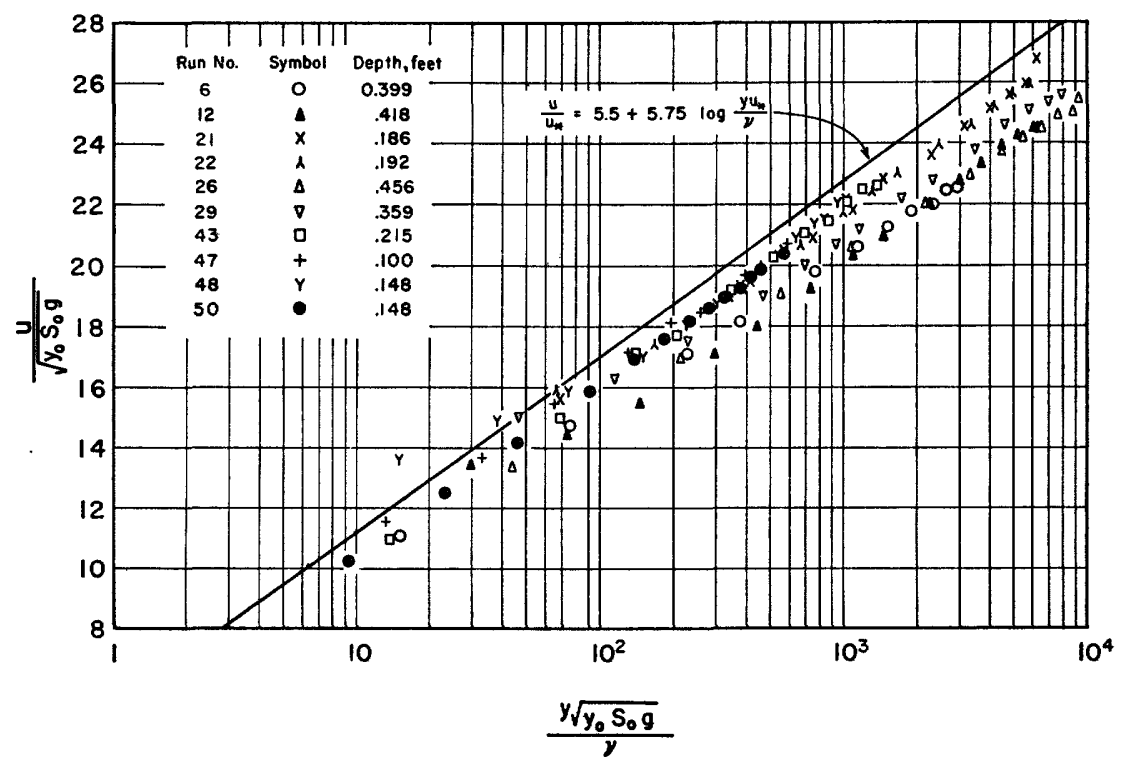

FIGURE 9.-Point velocity in central region related to local wall shear. 
The lines do not have a common slope. At the smaller depths, a limiting slope of 5.75 is approached, which is the same as that of the Kármán-Prandtl relationship, equation (2), for flow in an infinitely wide channel. At the greater depths, farther from the infinitely wide case, the slopes become smaller.

By relating the point velocities to the average wall shear stress over the flume perimeter, the data of figure 9 may be plotted upon the single logarithmic curve of figure 10. The function shown upon the ordinate scale of the figure is the ratio of point velocity to average shear velocity, $\bar{u}_{*}=\sqrt{R S_{0} g}$; the abscissa function is the same as for figure 10. The line through the points is described by the equation

$$
\frac{u}{\bar{u}_{*}}=5.50+5.75 \log \frac{y u_{*}}{\nu}
$$

The constants of equation (8) are numerically equal to those of the Kármán-Prandtl expression, equation (2).

Equation (8) may be integrated over the central region to obtain an expression for the mean velocity in the region. This gives:

$$
\frac{U_{c}}{\bar{u}_{*}}=3.00+5.75 \log \frac{y_{0} u_{*}}{\nu}
$$

The distribution of mean velocity in the rectangular flume section is shown in dimensionless form in figure 11, in terms of the ratio

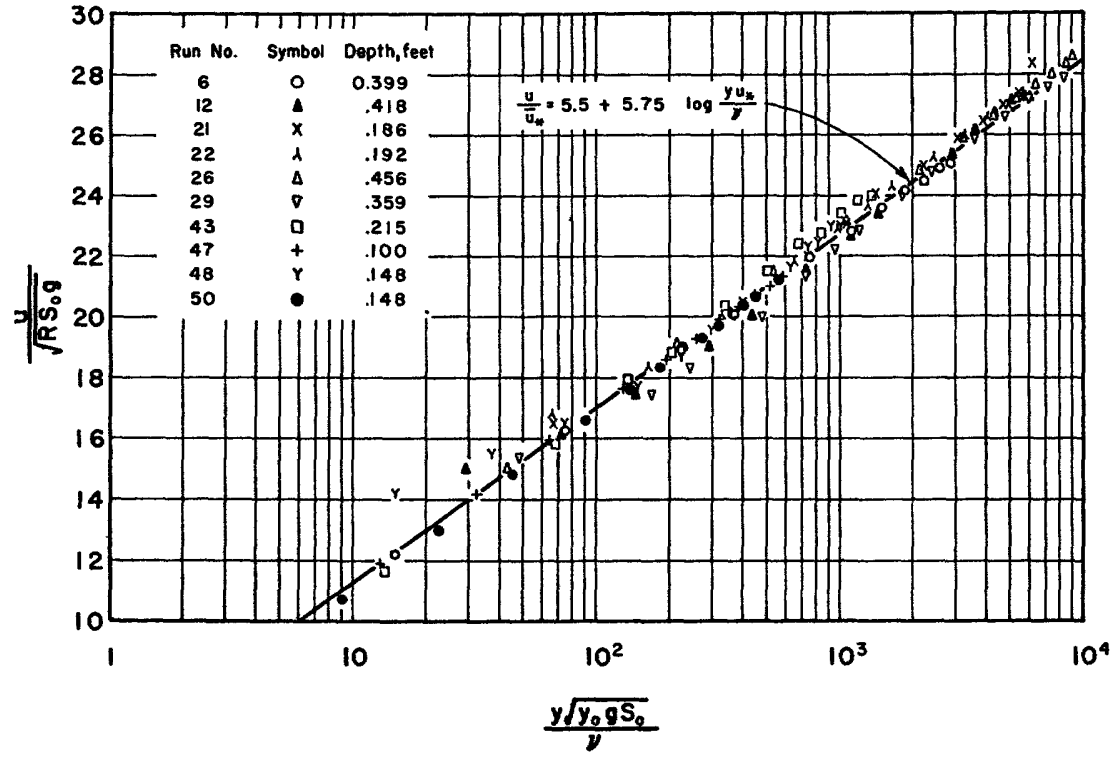

Figure 10.-Point velocity in central region related to average wall shear. 


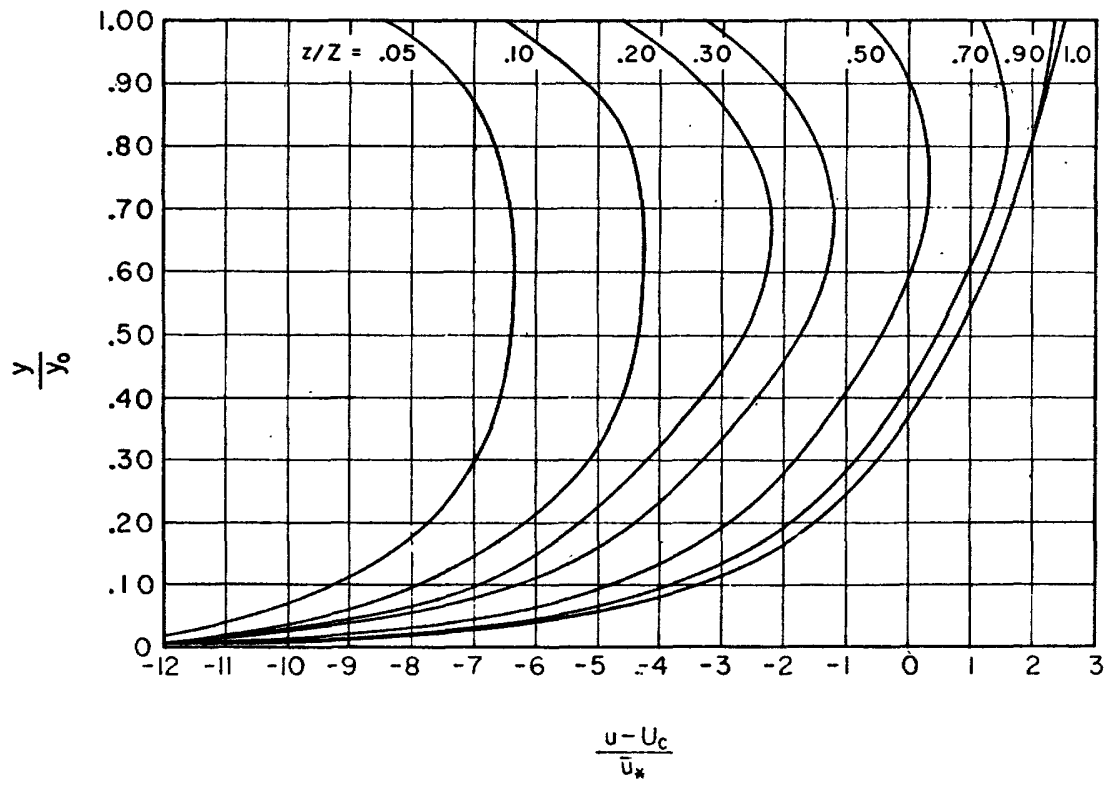

Ficure 11.-Dimensionless velocity distribution.

$y / y_{0}$ and the ratio $\left(u-U_{c}\right) / \bar{u}_{*}$. The curves are for various values of the ratio $z / Z$, where $z$ is distance from the sidewall, and $Z$ is the distance from the sidewall to the central region boundary. The curves were interpolated from the point-velocity observations; the coordinates of the points at which the data were taken did not always correspond to the coordinates of the points through which the dimensionless curves are drawn. The data may not therefore be conveniently shown.

The curve for which $z / Z=1.0$ corresponds to equation (8). The algebraic expression for the curve may be obtained by subtracting equation (9) from equation (8). The resulting equation is:

$$
\frac{u-U_{c}}{\bar{u}_{*}}=2.50+5.75 \log \frac{y}{y_{0}}
$$

The reversal of the curves near the surface in the wall region is an undication of transverse motion which proceeds outward from the vicinity of the wall. Visual observation of small objects immersed in the flow at various points in the wall region lead to no very definite conclusions concerning the pattern of the secondary flow. 


\section{A-18 LABORATORY STUDIES OF OPEN-CHANNEL FLOW}

\section{REFERENCES CITED}

Boussinesq, T. V., 1877, Theorie de l'écoulement tourbillant, Mém. préséntes par divers savant Académie des sciences, v. XXIII, Paris.

Prandtl, L., 1925, Utber die ausgebildete Turbulenz, Zeitschr. Angew. Math. u. Mech., v. 5, p. 136.

Taylor, G. I., 1935, Statistical theory of turbulence, Proc. Roy. Soc. London A, v. 151, No. 183.

Von Kármán, Th., 1931, Mechanische Ähnlichkeit und Turbulenz, NACA Tech. Memo. No. 611.

Nikuradse, J., 1932, Gesetzmässigkeiten der Turbulenten Strömung in glatten Rohren, Forschg. -Arb. Ing.-Wesen. No. 356.

Rouse, Hunter, ed., 1959, Advanced mechanics of fluids, New York, John Wiley and Sons. 